\title{
The Value of a Learner's Stance: Lessons Learned from Pregnant and Parenting Women
}

\author{
Larry Humbert, MSSW, PgDip, Executive Director, Indiana Perinatal Network \\ Theresa L. Roberts, Ph.D., MSW, ACSW, LCSW, Associate Professor, Indiana \\ University School of Social Work
}

\begin{abstract}
The voices, perspectives, and experiences of pregnant and parenting women are vital sources of information often overlooked or not understood by professionals. By the end of the poster presentation participants will: (1) understand access to maternal and child health services from the perspectives of diverse consumers; (2) utilize patients direct quotes and experiences to identify strategies to enhance the quality of access; and, (3) identify key dimensions influencing patient experiences, including health status and needs, significant others, cultural beliefs, and provider and organizational factors.
\end{abstract}

Twenty-four focus groups were conducted with 143 urban women, ages 14-45, who were primarily Medicaid consumers. Maternal and child health organizations in Marion and Lake Counties providing primary or secondary services recruited African American, Caucasian, and Latina pregnant and parenting women. When possible, groups were stratified by race, ethnicity and age to encourage their engagement.

The following five themes on access and quality of participants' maternal and child health experiences emerged: (1) the primary role that personable and caring health providers and staff played in accessing services; (2) provider recommendations were oftentimes discounted as irrelevant; (3) alternative health practices were motivated by a genuine desire to help themselves or their children; (4) agency practices and policies were sometimes perceived as potentially discriminatory; and , (5) consumers identified unresolved feelings regarding pregnancy.

These findings can assist providers to develop genuine relationships and address the unique cultural needs of their patients. Recommended actions include assuming a learner's stance as a way of developing an increased understanding of patients' underlying motives, perceptions of alternative health practices of their patients, and identifying the role and impact of their patient's social network.

Humbert, L., \& Roberts, T.L. (2009, September). “The Value of a Learner's Stance: Lessons Learned from Pregnant \& Parenting Women”. Maternal and Child Health Journal 13(5), p.588596. 